\title{
PERCURSOS DO ACESSO AO PROEJA: UM PANORAMA DO IFFLUMINENSE
}

\section{J. H. DA S. PESSANHA ${ }^{1}$ e G. T. DO CARMO ${ }^{2}$}

Instituto Federal de Educação, Ciência e Tecnologia Fluminense ${ }^{1}$, Universidade Estadual do Norte Fluminense

Darcy Ribeiro ${ }^{2}$

josihsp@gmail.com ${ }^{1}$

Submetido 06/06/2017 - Aceito 15/04/2020

DOI: $10.15628 /$ holos.2020.5992

\section{RESUMO}

Este artigo analisa a política de acesso dos estudantes ao Programa Nacional de Integração da Educação Profissional com a Educação Básica na Modalidade da Educação de Jovens e Adultos (PROEJA) no Instituto Federal de Educação, Ciência e Tecnologia Fluminense campus Campos Guarus. A partir da sistematização dos editais dos processos seletivos para os cursos do PROEJA, realizou-se um estudo dos procedimentos e critérios adotados nessa ação. Foi verificado que houve mudanças e investimentos na perspectiva da inclusão. Entretanto, é necessário rever alguns elementos, que podem determinar que as ações investidas nesses processos seletivos sejam de fato consolidadas institucionalmente.

PALAVRAS-CHAVE: Acesso, direito à educação, Programa Nacional de Integração da Educação Profissional com a Educação Básica na Modalidade da Educação de Jovens e Adultos.

\section{ROUTES TO ACCESSING PROEJA: AN OVERVIEW OF IFFLUMINENSE}

\begin{abstract}
This article discusses the access policy to students to the National Program for the Integration of Professional Education with Basic Education in the Youth and Adult Education modality (PROEJA, abbreviation in Portuguese) at the Instituto Federal de Educação, Ciência e Tecnologia Fluminense - Campos Guarus campus. Considering the systematization of public notices of selection processes
\end{abstract}

for the PROEJA courses, a study was conducted regarding the procedures and criteria employed in this action. Changes and investments were observed with a view to inclusion. It is necessary, however, to review some elements, which may determine whether the actions taken in these selection processes are indeed institutionally consolidated.

KEYWORDS: Access, rights to education, Basic Education in the Youth and Adult Education modality. 


\section{INTRODUÇÃO}

O objetivo deste estudo foi analisar os editais dos processos seletivos para acesso/ingresso dos estudantes nos cursos do Programa Nacional de Integração da Educação Profissional com a Educação Básica na Modalidade da Educação de Jovens e Adultos - PROEJA, no Instituto Federal de Educação, Ciência e Tecnologia Fluminense (IFFluminense), especificamente campus Campos Guarus.

A investigação pautou-se numa análise qualitativa, que se materializou através de uma pesquisa documental (Gil, 2002). Foi realizado o levantamento e leitura dos editais e resultados finais dos processos seletivos no período de 2007-2014', identificando regras, critérios, procedimentos e ações para admissão dos candidatos aos cursos do PROEJA.

Metodologicamente, para coleta de dados, foi realizada uma entrevista focalizada dirigida a um servidor que esteve envolvido na gestão e elaboração dos processos seletivos para acesso aos cursos do PROEJA no IFFluminense. O objetivo desse tipo de entrevista é captar "[...] a atenção em determinada experiência e seus efeitos" (Selltiz, Cook, \& Wrightsman, 1975, p. 295). Com vistas a preservar a identidade do entrevistado, não utilizamos o nome do servidor participante, atribuindoIhe uma abreviação fictícia.

Este artigo está dividido em três partes: no primeiro tópico, abordamos os principais aspectos para a consolidação do PROEJA, enquanto política pública. No segundo tópico, descrevemos as análises da investigação, com base nos documentos e registros levantados, como também, consideramos a percepção do servidor entrevistado durante o processo de pesquisa. Por último, desenvolvemos as considerações finais.

\section{PONTOS DE REFLEXÃO SOBRE O PROEJA}

A criação do Programa Nacional de Integração da Educação Profissional com a Educação Básica na Modalidade de Educação de Jovens e Adultos - PROEJA aconteceu no ano de 2005, e emerge da necessidade de atendimento a um contingente representativo de jovens e adultos, acima de 18 anos, que não possuem escolaridade básica.

Num primeiro momento, na perspectiva de minimizar as desigualdades sociais e fortalecer a cidadania, o PROEJA apresenta-se enquanto um programa governamental, durante o período do 10 mandato do presidente Luiz Inácio Lula da Silva (2004-2007), e se propõe a transformar-se em política pública em atendimento aqueles que foram excluídos do sistema educacional ou não tiveram acesso na idade denominada regular.

A confluência dos campos da educação de jovens e adultos (EJA), educação básica (EB) e educação profissional (EP) constitui um dos principais desafios para estabilizar o PROEJA enquanto política pública. O diálogo entre essas dimensões é uma iniciativa inovadora no percurso educacional brasileiro, tanto no nível fundamental quanto no nível médio. Nessa visão, para Moll (2010, p. 134), essa aproximação significa "[...] produzir um campo epistemológico, pedagógico e curricular novo" na perspectiva da reflexão e relação com a prática educativa e política. 
O diálogo entre as instituições envolvidas com essa iniciativa de integração entre EJA, EB e EP deve ser estimulado. Dentre elas estão: a Rede EPT (Educação Profissional e Tecnológica), os sistemas estaduais e municipais de ensino e as instituições ligadas ao "Sistema $S$ " que poderão consolidar itinerários formativos na tentativa de possibilitar maior oferta qualificada de oportunidades educacionais que atendam a demanda potencial de jovens e adultos.

Nesse sentido, Frigotto (2010, p. 39) defende a criação de um:

Sistema ou Subsistema Nacional de Formação/Qualificação Profissional, como política pública, articulando as múltiplas redes existentes e vinculado às diferentes demandas do processo produtivo, à política de criação de emprego e renda e, no contexto que ainda nos encontramos, à política pública de educação de jovens e adultos.

Entretanto, em curto prazo, determinadas formas de redimensionamento são emergentes para que o PROEJA se estabeleça sobre os princípios que norteiam sua ação. Isso significa assumir ideologicamente novos rumos institucionais, dentre eles, Moll (2010, p. 135, grifos nossos) destaca os seguintes:

a) dos modos de acesso às instituições de ensino: o retorno à escola não é uma tarefa simples para quem já deixou de ser estudante há muito tempo ou que saiu por ver expectativas exauridas e sonhos frustrados. É preciso trazer esses estudantes de volta a escola, facilitando as formas de acesso. No caso das instituições federais de educação profissional, ciência e tecnologia (IFETS), é preciso modificar o consagrado e praticado processo de vestibular [...] Trata-se de derrubar as barreiras que dificultam a aproximação desses estudantes com a escola; b) dos mecanismos de permanência: não há como imaginar que o acesso garantirá a permanência, por isso há que se prever estratégias para manutenção da continuidade da trajetória escolar [...]; c) da relação do ensino com o sucesso escolar e a garantia da aprendizagem: entrar, permanecer e aprender implicam uma mudança de fundo, uma mudança no olhar do professor na direção dos estudantes para superação da profecia que se "autorrealiza" e que reproduz no cotidiano da sala de aula olhares, falas e gestos que dão conta da descrença do professor em relação aos estudantes e a sua capacidade de aprender.

Outro desafiante aspecto que permeia os objetivos do PROEJA é o atendimento a um público diversificado e heterogêneo. São homens e mulheres, trabalhadores e desempregados, jovens, adultos e idosos, estudantes com trajetórias escolares descontínuas, sujeitos com experiências de fracasso escolar ou que buscam resgatar o "tempo perdido", estudantes que foram privados de direitos sociais, indivíduos que almejam novas oportunidades na vida. Para Lima Filho (2010, p. 115 apud Maron, 2009), esse público plural necessita "[...] ser acolhido pela escola e integrados como sujeitos dos processos de ensino e aprendizagem e não simplesmente como objetos de uma ação educativo-formativa". Evitando, inclusive, novos processos de exclusões.

Segundo Moll (2010, p. 136), “[...] a complexidade desses desafios requer a combinação da ação, do saber e da vontade de professores(s) e gestores(as), como sujeitos de uma história cotidiana, para construir a afirmação do PROEJA, como pedagogia e como política".

A postura da escola/instituição que se propõe a ministrar essa oferta de ensino tende a ressignificar suas práticas cotidianas, com vistas à qualidade da educação oferecida aos jovens e adultos que estão incluídos nesse processo. 
Por ser considerada uma iniciativa pioneira (Lima Filho, 2010, p. 114), o PROEJA requer o atendimento de necessidades nos aspectos infraestruturais, de práticas pedagógicas e metodológicas para formação de professores que se encontra em construção. De acordo com Moll (2010, p. 138), "é preciso considerar a necessidade de fazermos o caminho, caminhando".

A definição da trajetória e formas de enfrentamentos para assumir esses desafios está mediada e condicionada à realidade dos sujeitos envolvidos nesse processo - professores, estudantes, gestores, funcionários - pelos recursos disponíveis, mas principalmente pela vontade de participação e diálogo da comunidade escolar com vistas a assumir essa política pública, que pressupõe comprometimento e adesão dos pares, considerando as singularidades do contexto educacional e institucional.

\section{ACESSO AO PROEJA NO IFFLUMINENSE}

A gratuidade e o acesso universal aos cursos oferecidos para o PROEJA é uma garantia prevista no Documento Base (Brasil, 2007) que norteia os parâmetros legais desta oferta pública educacional.

Cabe à instituição federal que oferece os cursos do PROEJA disponibilizar a oferta de vagas na forma de "edital público, podendo a seleção ser realizada por meio de processo seletivo simplificado, sorteio, entrevistas ou a combinação de vários instrumentos seletivos ou outros meios que a escola venha a adotar, considerando-se, imprescindivelmente, a condição de democratização do acesso" (BRASIL, 2007, p. 59).

Conforme aponta o Documento Base (2007, p. 59) do PROEJA, as exigências para ingresso (inscrição e matrícula) de interessados nos cursos desta natureza são: “a) ter ensino fundamental concluído e b) ter idade compatível com a definida no projeto e em conformidade com a legislação sobre EJA (Parecer CNE/CEB n. 11/2000 e Resolução CNE/CEB n. 01/2000)", ou seja, maior de 18 anos.

Para fins deste artigo, coube uma sistematização dos editais dos processos seletivos realizados para ingresso nos cursos do PROEJA no Instituto Federal Fluminense campus Campos Guarus, no período compreendido entre 2007 e 2014. Conforme explicitado na Figura (1), descrevemos os procedimentos de seleção adotados no período citado: 


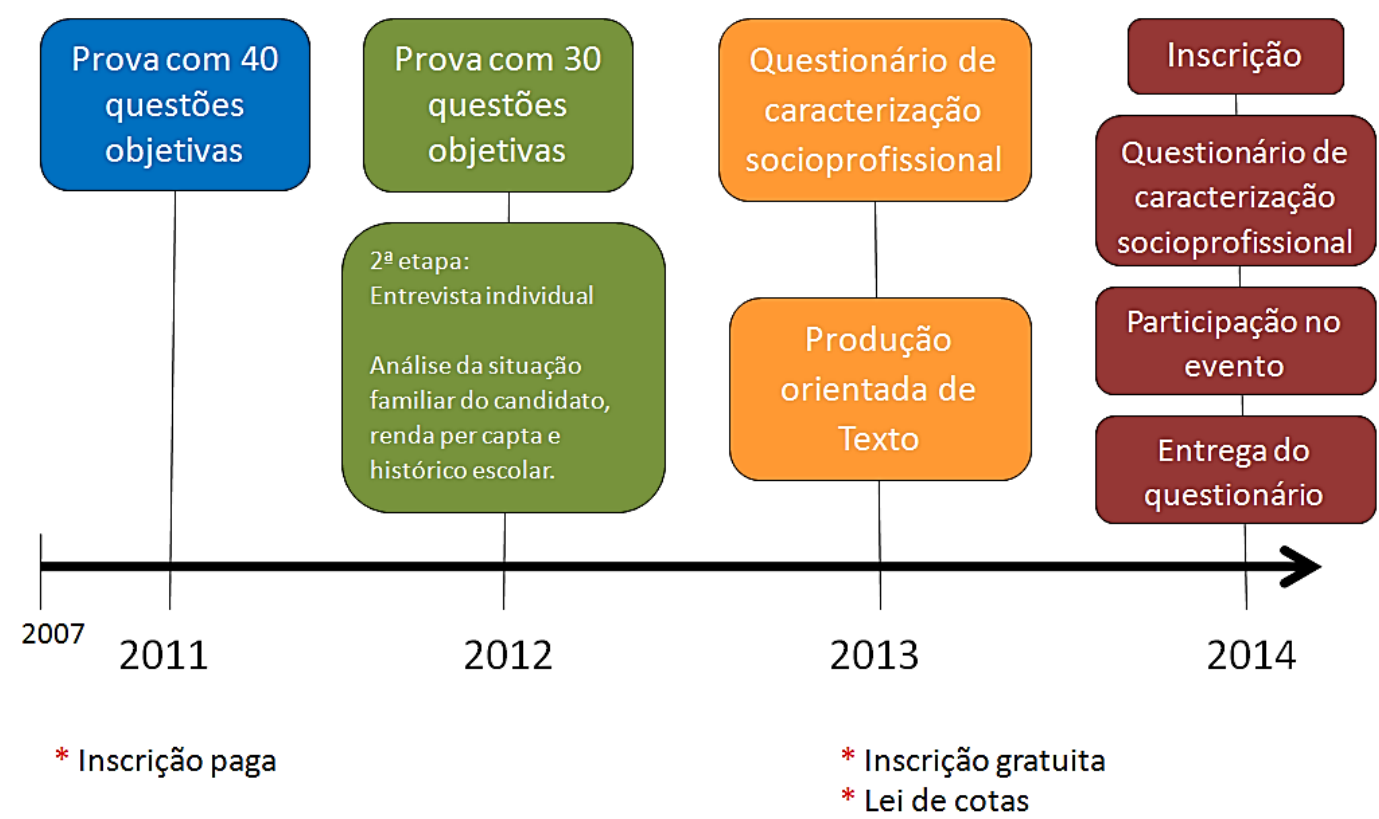

Figura 1: Descrição das formas de seleção adotadas no PROEJA no IFFluminense campus Campos Guarus.

No período compreendido de 2007 a 2011, os processos seletivos foram organizados nos mesmos "moldes" adotados para os cursos técnicos regulares diurnosii. O sistema meritocrático se estabeleceu, no período citado, como parâmetro para ingresso no PROEJA. Na opinião de Lemos (2010, p. 111), esse critério não é compatível com o princípio da equidade, pois "não prioriza formas de acesso cujos critérios atendam as diversidades e sejam inclusivos, ao contrário, perpetua-se um modelo que promove a seleção daqueles que comprovaram exclusivamente pela prova objetiva de conhecimentos relativos ao ensino fundamental [...]".

Coutinho (2012, p. 14) corrobora essa análise, pois, em sua pesquisa, identificou que o modelo padrão adotado pelo processo seletivo meritocrático, "[...] não dialoga com o saber do aluno trabalhador, e por hipótese pode-se considerar, que tende a excluir os sujeitos da EJA que, comumente têm como característica a descontinuidade dos estudos no ensino fundamental".

Para Lemos (2010, p. 79), a equidade enquanto fundamento para a garantia do direito ao acesso aos cursos relativos ao PROEJA precisa "[...] ter contornos diferenciados e precisa estar revelada por meio de critérios que subvertam algumas regras que atendem apenas a uma parcela da sociedade e não a todos com igual qualidade".

Os trâmites tradicionais de seleção, que historicamente foram utilizados, por meio de prova com questões objetivas de múltipla escolha, referentes às grandes áreas de conhecimento (Língua Portuguesa, Matemática, Física, Química, Biologia, História e Geografia), foram medidas adotadas no PROEJA que, num primeiro momento, não se atentaram para o seu público-alvo.

A partir do aprofundamento dos princípios filosóficos e teórico-metodológicos que orientam as práticas acadêmicas no IFFluminense, o movimento de mudança no processo seletivo para acesso aos cursos do PROEJA começa a acontecer a partir do edital do ano letivo de 2012, explicitado na Figura (1). Mesmo persistindo a seleção com a prova tradicional, acrescentaram-se as entrevistas individuais com os candidatos buscando analisar sua situação familiar, renda per capita e histórico escolar. 
A Diretoria do Departamento de Tecnologias Sociais e EJA composta na Reitoria do IFFluminense construiu a Regulamentação do acesso aos cursos técnicos integrados ao ensino médio na modalidade de Educação de jovens e adultos naquele ano, um documento norteador das ações nos campi do Instituto.

$\mathrm{Na}$ regulamentação estava prevista que as entrevistas individuais comporiam a segunda etapa do processo seletivo de 2012 , conforme descrito no edital n. 32/2011. O Art. 8 o da referida Regulamentação previa que "cada campus deverá constituir uma equipe de profissionais para a realização das entrevistas, com a presença obrigatória de representante do Serviço Social".

O objetivo da etapa das entrevistas (peso 20 pontos) foi identificar aqueles candidatos que classificados na prova objetivaiii, se enquadravam nos seguintes critérios:

Quadro 1: Critérios para classificação na entrevista no processo seletivo ano letivo 2012 - IFFluminense campus Campos Guarus

\begin{tabular}{|c|c|}
\hline CRITÉRIO & PONTUAÇÃO \\
\hline \multicolumn{2}{|l|}{ FILHOS menores de 18 anos } \\
\hline Sim & 2 \\
\hline Não & 0 \\
\hline \multicolumn{2}{|l|}{ SITUAÇÃO DE TRABALHO } \\
\hline Desempregado & 5 \\
\hline Trabalho informal & 4 \\
\hline Trabalho formal & 3 \\
\hline Não trabalho e meus gastos são custeados & 1 \\
\hline \multicolumn{2}{|l|}{ RENDA PER CAPITA FAMILIAR } \\
\hline Não tem renda per capita familiar & 5 \\
\hline < 01 salário mínimo & 4 \\
\hline 01 salário mínimo & 3 \\
\hline De 02 a 03 salários mínimos & 1 \\
\hline \multicolumn{2}{|l|}{ GRAU DE ESCOLARIDADE } \\
\hline Somente Ensino Fundamental & 5 \\
\hline \multicolumn{2}{|l|}{ ESCOLA DE ORIGEM } \\
\hline Curso Fundamental totalmente cursado em escola pública de EJA & 2 \\
\hline Curso Fundamental cursado, no mínimo, 50\% em escola pública de EJA & 1,5 \\
\hline Curso Fundamental totalmente cursado em escola pública & 1 \\
\hline Curso Fundamental cursado, no mínimo, 50\% em escola pública & 0,5 \\
\hline \multicolumn{2}{|l|}{ PARTICIPAÇÃO EM PROGRAMAS SOCIAIS } \\
\hline Sim & 1 \\
\hline Não & 0 \\
\hline
\end{tabular}

Fonte: Regulamentação do acesso aos cursos técnicos integrados ao ensino médio na modalidade de Educação de jovens e adultos - IFFluminense - 2011/2012.

Observamos no Quadro 1, que a proposta reformulada de ingresso aos cursos passa a considerar e priorizar candidatos que tenham filhos menores de 18 anos, desempregados, sem renda familiar, oriundos do ensino fundamental, sendo preferencialmente da rede pública na modalidade EJA e beneficiários de programas sociais.

Os ajustes promovidos para o ano de 2012 avançaram relativamente, na tentativa de se buscar atender o público-foco previsto na política pública, considerando as características de jovens 
e adultos presentes na EJA, na hipótese de alcançar uma "[...] política afirmativa de direitos de coletivos sociais, historicamente negados" (Arroyo, 2011, p. 29).

No que tange à entrevista para levantamento de dados sobre o tema, para a servidora $\mathrm{R}$ entrevistada na pesquisa, sua percepção a respeito da mudança no processo seletivo de entrada em 2012 foi de que, "...teve-se um avanço em 2011, ele já foi um movimento interessante, mas ele não conseguiu romper com a prova. Não conseguiu mergulhar na questão da inclusão. Ele tentou fazer a meia, por que é isso mesmo, é a questão do paradigma. [...] Só que assim... um processo a gente só consegue avaliar na medida que ele acontece e que ele produz resultado. Então, eles tiveram um esforço muito interessante, eu achei muito importante" (Entrevistada R./Junho-2015).

As dificuldades encontradas nesse primeiro momento de mudança no processo seletivo de 2012 foi o comparecimento dos candidatos para as entrevistas logo após a divulgação do resultado classificatório das provas objetivas. Houve um alto índice de faltosos, o que implicou a divulgação de um novo edital para as vagas remanescentes ${ }^{\mathrm{iv}}$.

No que se referem às ações afirmativas, presentes nos processos seletivos realizados no período de 2007 a 2011 (discriminados no Quadro 2), foi possível identificar que buscou-se beneficiar aqueles candidatos trabalhadores formais, ou seja, com carteira assinada comprovada, como também aqueles candidatos residentes à margem esquerda do Rio Paraíba do Sul, priorizando os moradores do Distrito de Guarusv. 
Quadro 2: Quadro descritivo sobre os Processos Seletivos para as vagas nos cursos do PROEJA - IFFluminense campus Campos Guarus - período: 2007 a 2014

\begin{tabular}{|c|c|c|c|}
\hline Ano & Cursos PROEJA & Vagas & Ações afirmativas \\
\hline 2007 & Eletrônica & 40 & $\begin{array}{l}\text { Candidatos com experiência profissional comprovada (4 pontos); Candidatos } \\
\text { residentes no Distrito de Guarus (4). }\end{array}$ \\
\hline 2008 & $\begin{array}{c}\text { Eletrônica } \\
\text { Meio ambiente }\end{array}$ & $40-40$ & \multirow{2}{*}{$\begin{array}{l}\text { Candidatos com experiência profissional comprovada, por um período de no mínimo } \\
1 \text { ano ( } 4 \text { pontos); Candidatos residentes no Distrito de Guarus ( } 4 \text { pontos). Candidatos } \\
\text { premiados na Olimpíada Brasileira de Matemática no ano de } 2006 \text { ou 2007, do Nível } \\
2 \text { (7a e } 8 \text { a séries) ou Nível } 3 \text { (Ensino Médio) serão classificados com adição de pontos } \\
\text { na prova escrita, correspondente a premiação: Medalha de ouro - } 8 \text { pontos; } \\
\text { Medalha de prata - } 4 \text { pontos; Medalha de bronze - } 2 \text { pontos; Menção honrosa - } 1 \\
\text { ponto. }\end{array}$} \\
\hline 2009 & $\begin{array}{c}\text { Eletrônica } \\
\text { Meio ambiente }\end{array}$ & $35-40$ & \\
\hline Ano & Cursos PROEJA & Vagas & Ações afirmativas \\
\hline 2010 & $\begin{array}{l}\text { Eletrônica } \\
\text { Meio ambiente }\end{array}$ & $35-40$ & \multirow{3}{*}{$\begin{array}{l}\text { Candidatos com experiência profissional comprovada, por um período de no mínimo } \\
1 \text { ano, devendo estar em efetivo exercício de suas funções no período de inscrição } \\
\text { (4 pontos); Candidatos residentes em bairros ou Distritos localizados a margem } \\
\text { esquerda do Rio Paraíba do Sul (4). }\end{array}$} \\
\hline 2011 & $\begin{array}{l}\text { Eletrônica } \\
\text { Meio ambiente }\end{array}$ & $35-40$ & \\
\hline 2012 & $\begin{array}{l}\text { Eletrônica } \\
\text { Meio ambiente }\end{array}$ & $35-40$ & \\
\hline 2013 & $\begin{array}{l}\text { Eletrônica } \\
\text { Meio ambiente }\end{array}$ & $35-40$ & $\begin{array}{l}\text { Sistema de cotas - } \mathbf{5 0} \% \text { das vagas: } \\
\text { Candidatos que cursaram todo o Ensino Fundamental em escola pública e renda } \\
\text { familiar per capita de até } 1 \text { salário mínimo e meio } \\
\text { cota } 1 \text { (preto, pardo e indígena) } \\
\text { cota } 2 \text { (outras etnias) } \\
\text { Candidatos que cursaram todo o Ensino Fundamental em escola pública e renda } \\
\text { familiar per capita maior que } 1 \text { salário mínimo e meio } \\
\text { cota } 3 \text { (preto, pardo e indígena) } \\
\text { cota } 4 \text { (outras etnias) } \\
\text { Seleção - critérios avaliados no questionário socioprofissional: } \\
\text { * Idade; * Forma de ensino e tipo de escola que concluiu o Ensino Fundamental; } \\
\text { * Tempo de afastamento da escola; } \\
\text { * Renda familiar. }\end{array}$ \\
\hline 2014 & $\begin{array}{l}\text { Eletrônica } \\
\text { Meio ambiente }\end{array}$ & $35-40$ & $\begin{array}{l}\text { Sistema de cotas - } \mathbf{5 0 \%} \text { das vagas: } \\
\text { Candidatos que cursaram todo o Ensino Fundamental em escola pública e renda } \\
\text { familiar per capita de até } 1 \text { salário mínimo e meio } \\
\text { cota } 1 \text { (preto, pardo e indígena) } \\
\text { cota } 2 \text { (outras etnias) } \\
\text { Candidatos que cursaram todo o Ensino Fundamental em escola pública e renda } \\
\text { familiar per capita maior que } 1 \text { salário mínimo e meio } \\
\text { cota } 3 \text { (preto, pardo e indígena) } \\
\text { cota } 4 \text { (outras etnias) } \\
\text { Seleção - critérios avaliados no questionário socioprofissional: } \\
\text { * Idade; * Forma de ensino e tipo de escola em que concluiu o Ensino Fundamental; } \\
\text { * Egressos de cursos de qualificação básica; } \\
\text { * Renda familiar; } \\
\text { * Situação em relação ao trabalho. }\end{array}$ \\
\hline
\end{tabular}

Fonte: Editais do processo seletivo 2007-2014, elaborado pela autora. 
Coutinho (2010), em sua pesquisa de Mestrado, analisou as ações afirmativas presentes em processos seletivos para acesso aos cursos em Instituições da Rede Federal. Para esse autor, as ações afirmativas são "[...] aquelas que visam ao rompimento de desigualdades históricas ou sociais, promovendo o acesso e a inclusão nos cursos técnicos das escolas da Rede Federal de Educação Profissional e Tecnológica - RFEPT" (Coutinho, 2010, p. 68).

No Brasil, há experiências inovadoras de ações afirmativas nos Institutos da Rede Federal, constatado na pesquisa de Coutinho (2010). Essas iniciativas visam a "[...] combater a alta taxa de seletividade social dos processos seletivos que se realizam com provas objetivas de múltipla escolha, considerando-se as ações afirmativas como sendo uma forma de reconhecimento do direito democrático de participação dos segmentos excluídos" (p. 69-70).

No caso do IFFluminense, as ações afirmativas presentes nos editais de 2007 a 2011, conforme descrito no Quadro 2, podem ser consideradas incompletas. Segundo Lemos (2010, p. 115), essas ações:

[...] não são equitativas, na medida em que não garantem o acesso democrático de todos os trabalhadores e nem é um critério para todos os jovens e adultos, e sim para aqueles que trabalham no mercado formal. Aqueles que estão no trabalho informal são autônomos ou estão temporariamente desempregados, ficam alijados desse critério que se pretende inclusivos.

Em 2012, a Diretoria de Desenvolvimento de Políticas Emancipatórias e Inclusão Social (DDPEIS) é criada no âmbito da reitoria do IFFluminense com o objetivo de promover, dentre outras atividades, diálogos e ações com vistas à democratização do acesso da classe trabalhadora à profissionalização e construção de mecanismos que promovam a oferta e percurso de formação para o trabalhador.

Nesse caso, a tentativa de se adequar novamente o processo seletivo ao público destinatário dos cursos do PROEJA persistiu no ano seguinte (2013). Com a corresponsabilidade pelo processo seletivo, a DDPEIS realizou uma revisão no edital que compunha os critérios de ingresso de modo a torná-los mais acessíveis ao público da EJA. Foi excluída a seleção por intermédio de prova e utilizaram-se dois instrumentos para análise do perfil dos candidatos: 1) O preenchimento do questionário de caracterização socioprofissional; e 2) A produção orientada de texto, com caráter classificatório.

Podemos observar no Quadro 2 que o edital para o ano letivo de 2013, também sofre as mudanças referentes às ações afirmativas, pois essas já se compunham na própria forma de seleção, quando foi realizado o estudo de caracterização socioprofissional dos candidatos e posterior análise de sua produção textual, enquanto critério de seleção daqueles que tinham perfil para os cursos do PROEJA.

E ainda referendando este edital de 2012 (ano letivo 2013) foi considerada a promulgação da Lei n. 12.711 de 29 de agosto de 2012, regulamentada pelo Decreto n. 7.824 de 11 de outubro de 2012, que indica a reserva de, no mínimo, 50\% do total de vagas para ingresso nos cursos ofertados pelos Institutos e Universidades Federais, delimitando a cota social e racial.

Tal lei vem reforçar um dos critérios estabelecidos para avaliação dos questionários de caracterização socioprofissional. Através dela, aqueles que estivessem cursando o Ensino 
Fundamental em escola pública poderiam ser priorizados para ingresso no PROEJA. Para além desse critério, a lei trouxe a cota racial e cota social, buscando a democratização do acesso a grupos que historicamente foram excluídos.

Nessa direção, as adequações e o desenho das ações afirmativas nos processos de seleção para os cursos do PROEJA no IFFluminense, a partir de 2013, foram importantes visando a incluir aquele público alvo pretendido pela política que, "[...] agora por força da Lei n. 12.711/2012, [...] precisam ser implementadas para cumprir o papel social para o qual foram instituídas" (Wandroski \& Colen, 2014, p. 178).

O preenchimento do questionário de caracterização socioprofissional, tinha como peso $60 \%$ da avaliação, com o intuito de analisar o perfil do candidato nos seguintes aspectos: dados pessoais, escolaridade, vida profissional e situação familiar. Já o instrumento de produção orientada de texto, cujo valor era de $40 \%$ de pontuação da avaliação, tinha como objetivo analisar prioritariamente a realidade social e história de vida do candidato, além de sua experiência ou interesse na área pretendida.

Os critérios estabelecidos para análise dos questionários estavam previstos no Art. 27 do Edital n. 130/2012, descritos no Quadro (3), a seguir apresentado:

\section{Quadro 3: Critérios para o estudo do questionário socioprofissional do processo seletivo para o PROEJA - campus Campos Guarus - Ano letivo 2013}

\begin{tabular}{|c|c|c|c|c|c|c|}
\hline CRITÉRIOS & \multicolumn{6}{|c|}{ PONTUAÇĀO } \\
\hline \multirow{2}{*}{$\begin{array}{lll}\text { Idade (no } & \text { dia } & \text { do } \\
\text { preenchimento } & & \text { do } \\
\text { questionário) } & & \end{array}$} & 18 a 23 anos & 24 a 30 anos & $\begin{array}{l}31 \mathrm{a} 41 \\
\text { anos }\end{array}$ & $\begin{array}{l}42 \text { a } 50 \\
\text { anos }\end{array}$ & Acima de 50 anos & \multirow[t]{2}{*}{ Total } \\
\hline & 7 pontos & 12 pontos & 15 pontos & 10 pontos & 5 pontos & \\
\hline \multirow{2}{*}{$\begin{array}{l}\text { Forma de ensino e tipo de } \\
\text { escola em que concluiu o } \\
\text { Ensino Fundamental }\end{array}$} & \multicolumn{2}{|c|}{ Ensino Regular } & $\begin{array}{l}\text { Ensino de } \\
\text { EJA privado }\end{array}$ & $\begin{array}{l}\text { Ensino de } \\
\text { EJA público }\end{array}$ & Exames supletivos & \\
\hline & \multicolumn{2}{|c|}{5 pontos } & 10 pontos & \multicolumn{2}{|c|}{15 pontos } & \\
\hline \multirow[t]{2}{*}{$\begin{array}{l}\text { Tempo em que está } \\
\text { afastado da escola }\end{array}$} & $\begin{array}{l}\text { Menos de } 1 \\
\text { ano }\end{array}$ & 1 a 2 anos & 2 a 5 anos & 5 a 10 anos & Mais de 10 anos & \\
\hline & 5 pontos & 7 pontos & 10 pontos & 12 pontos & 15 pontos & \\
\hline \multirow{2}{*}{$\begin{array}{l}\text { Renda Familiar per } \\
\text { capita, incluindo valores } \\
\text { relativos à bolsas sociais } \\
\text { (salário mínimo } \\
\text { R\$622,00) }\end{array}$} & $\begin{array}{l}\text { Até } 1 \text { salário } \\
\text { mínimo }\end{array}$ & $\begin{array}{l}\text { De 1 a 2 } \\
\text { salários } \\
\text { mínimos }\end{array}$ & $\begin{array}{l}\text { De } 2 \text { a } 3 \\
\text { salários } \\
\text { mínimos }\end{array}$ & $\begin{array}{l}\text { De } 3 \text { a } 4 \\
\text { salários } \\
\text { mínimos }\end{array}$ & $\begin{array}{l}\text { Mais de } 4 \text { salários } \\
\text { mínimos }\end{array}$ & \\
\hline & 15 pontos & 12 pontos & 10 pontos & 7 pontos & 5 pontos & \\
\hline $\begin{array}{l}\text { Produçăo orientada de } \\
\text { texto }\end{array}$ & \multicolumn{5}{|c|}{40 pontos } & \\
\hline $\begin{array}{l}\text { TOTAL DE } \\
\text { PONTOS }\end{array}$ & & & & & & \\
\hline
\end{tabular}

Fonte: Edital n. 130/2012

Com base no quadro, observa-se que os candidatos oriundos de ensino público da EJA e de Exames Supletivos, com idade entre 31 e 41 anos, que tinham mais de 10 anos de afastamento da escola e renda familiar per capita inferior a 1 salário mínimo, foram elencados nesse processo como perfil prioritário para serem contemplados entre as vagas, uma vez que o somatório total desses quesitos chegava a 60 pontos. Isso não significa que os candidatos aprovados tinham exatamente esse perfil, mas foram critérios utilizados para tentar chegar ao perfil desejado no PROEJA.

Até o processo seletivo do ano letivo de 2012, os interessados a se candidatar às vagas pagaram a taxa de inscrição ou solicitavam isenção da taxa nos casos em que ele comprovasse que era beneficiário do Programa Bolsa Escola/Bolsa Família. A partir de 2013, as inscrições passaram a 
ser gratuitas, constituindo-se numa das mudanças encaminhada pela DDPEIS à Comissão do Processo Seletivo.

Com relação à análise das produções de texto para ingresso no ano letivo de 2013, buscaramse avaliar qualitativamente os dados apresentados pelo candidato no questionário, além de possíveis relações com a redação desenvolvida. A produção textual voltava-se para descrição de informações relevantes para o ingressante no que diz respeito a sua história de vida, sonhos, expectativas, interesses pessoais e profissionais que pudessem ter conexão com a sua entrada no IFFluminense.

As dificuldades encontradas nesse processo de 2013 ocorreram após a data de aplicação dos questionários, quando os candidatos deveriam apresentar os documentos comprobatórios para o estudo analítico das informações apresentadas, conforme explicitado em edital. Ocorreu que muitos candidatos não entregaram a documentação solicitada, impedindo que a equipe incumbida de analisar os documentos pudesse concluir corretamente sua pontuação nos quesitos necessários para classificação do resultado do processo seletivo. Ao final do referido processo, os candidatos aprovados deveriam participar da palestra sobre o PROEJA, antes da confirmação de sua matrícula.

Já o processo seletivo referente ao ano letivo de 2014 também sofreu alteração. A ação afirmativa com base no sistema de cotas se manteve, destinando $50 \%$ das vagas para candidatos oriundos de escola pública, assim como a cota racial e social, consoante previsto em lei. Entretanto, os critérios avaliados no questionário socioprofissional passaram a priorizar, além da faixa etária, a forma de ensino e tipo de escola de conclusão do Ensino Fundamental e a renda familiar; incluindo para tanto, dois indicadores: egressos de cursos de qualificação básica e situação referente ao trabalho. Exclui-se então, o indicador: tempo de afastamento da escola, conforme indicado no processo anterior, Quadro (4).

Quadro 4: Critérios para o estudo do questionário socioprofissional do processo seletivo para o PROEJA - campus Campos Guarus - Ano letivo 2014

\begin{tabular}{|c|c|c|c|c|c|c|}
\hline CRITÉRIOS & \multicolumn{5}{|c|}{ PONTUAÇÃO } & Total \\
\hline \multirow{2}{*}{$\begin{array}{l}\text { Idade (no dia do } \\
\text { preenchimento do } \\
\text { questionário) }\end{array}$} & 18 a 23 anos & 24 a 30 anos & $\begin{array}{c}31 \text { a } 41 \\
\text { anos }\end{array}$ & $\begin{array}{l}42 \text { a } 50 \\
\text { anos }\end{array}$ & Acima de 50 anos & \\
\hline & 8 pontos & 15 pontos & 20 pontos & 12 pontos & 5 pontos & \\
\hline \multirow{2}{*}{$\begin{array}{l}\text { Forma de ensino e tipo de } \\
\text { escola em que concluiu o } \\
\text { Ensino Fundamental }\end{array}$} & \multicolumn{2}{|c|}{ Ensino Regular } & $\begin{array}{l}\text { Ensino de } \\
\text { EJA privado }\end{array}$ & $\begin{array}{l}\text { Ensino de } \\
\text { EJA público }\end{array}$ & Exames supletivos & \\
\hline & \multicolumn{2}{|c|}{10 pontos } & 15 pontos & \multicolumn{2}{|c|}{20 pontos } & \\
\hline \multirow{2}{*}{$\begin{array}{l}\text { Egressos dos Cursos de } \\
\text { Qualificação Básica } \\
\text { (PRONATEC, Mulheres } \\
\text { Mil ou CERTIFIC) ** }\end{array}$} & \multicolumn{3}{|c|}{ Cursos em áreas/eixos afins ${ }^{*}$} & \multicolumn{2}{|c|}{ Cursos em áreas/eixos não afins } & \\
\hline & \multicolumn{3}{|c|}{20} & \multicolumn{2}{|c|}{10} & \\
\hline \multirow{2}{*}{$\begin{array}{c}\text { Renda Familiar, incluindo } \\
\text { valores relativos à bolsas } \\
\text { sociais (salário mínimo } \\
\text { R\$678,00) }\end{array}$} & $\begin{array}{l}\text { Até } 1 \text { salário } \\
\text { mínimo }\end{array}$ & $\begin{array}{l}\text { De } 1 \text { a } 2 \\
\text { salários } \\
\text { mínimos }\end{array}$ & $\begin{array}{l}\text { De } 2 \text { a } 3 \\
\text { salários } \\
\text { mínimos }\end{array}$ & $\begin{array}{l}\text { De } 3 \text { a } 4 \\
\text { salários } \\
\text { mínimos }\end{array}$ & $\begin{array}{l}\text { Mais de } 4 \text { salários } \\
\text { mínimos }\end{array}$ & \\
\hline & 20 pontos & 15 pontos & 12 pontos & 8 pontos & 5 pontos & \\
\hline \multirow[t]{2}{*}{$\begin{array}{l}\text { Situação em relação ao } \\
\text { Trabalho }\end{array}$} & $\begin{array}{l}\text { Trabalho } \\
\text { Formal }\end{array}$ & $\begin{array}{l}\text { Trabalho } \\
\text { informal }\end{array}$ & $\begin{array}{l}\text { Desemprega } \\
\text { do }\end{array}$ & $\underset{\text { reabilitação }}{E m}$ & Aposentado & \\
\hline & 8 & 12 & 20 & 15 & 5 & \\
\hline \multicolumn{6}{|l|}{ TOTAL DE PONTOS } & \\
\hline
\end{tabular}

Fonte: Edital n. 127/2013.

Os candidatos, no processo seletivo de 2014, tiveram que realizar uma inscrição presencial para retirada do questionário socioprofissional no campus e, após preenchê-lo, deveria comparecer ao evento de apresentação do PROEJA com os documentos comprobatórios em envelope. Os 
candidatos também poderiam fazer a inscrição online, desde que imprimissem o questionário, preenchessem e organizassem os documentos, conforme previsto no edital. A intenção foi de simplificar o processo, para que aqueles que realmente tinham interesse pelos cursos ofertados comparecessem ao evento, que consistiu numa palestra informativa a respeito do PROEJA. Ao final do evento, após os esclarecimentos gerais a respeito do funcionamento institucional e dos cursos oferecidos, o candidato estaria munido de informações para tomada de decisão pela sua inscrição.

No último processo seletivo, observou-se que a intenção da gestão foi incentivar os alunos oriundos de cursos de qualificação, inclusive oriundos do próprio instituto, tendo em vista a efervescência de cursos promovidos por programas governamentais, como: Mulheres Mil, Pronatec e Certific, buscando resgatar o itinerário formativo dos jovens e adultos em processo de escolarização e profissionalização. Além desses, outros critérios complementavam a variável da faixa etária, entre elas, estava a situação de trabalho (classificando prioritariamente aqueles que estavam em situação de desemprego, como também aqueles com baixa renda familiar) e a situação de origem de sua escolaridade (classificando prioritariamente aqueles que eram oriundos do ensino público de EJA ou do ensino supletivo).

Entretanto, no dia marcado para apresentação dos documentos comprobatórios e participação do evento programado para tal finalidade, apenas 50 (cinquenta) candidatos compareceram, provocando a necessidade de publicação de um novo edital de vagas remanescentes ${ }^{\mathrm{vi}}$.

Os movimentos de mudanças ocorridos nos processos seletivos do IFFluminense, de certa forma, ocorreram com o objetivo de promover a possibilidade de acesso à educação profissional dos grupos sociais em condições desfavoráveis e/ou condições socioeconômicas comprometidas, buscando resgatá-los para ingresso no PROEJA. De acordo com a proposta da DDPEIS, as estratégias pautavam-se em favorecer a democratização do acesso à formação profissional com qualidade.

No que diz respeito à análise quantitativa dos resultados finais dos processos seletivos realizados entre 2007 e 2014, constatou-se que houve uma similaridade entre os cursos ofertados (Técnico em Eletrônica e Técnico em Meio Ambiente) na relação candidato $x$ oferta de vagas no decorrer do período. Houve um movimento crescente da procura por vagas entre 2007 e 2010, um aumento decrescente com relação ao número de candidatos interessados entre 2011 e 2012 e um novo aumento da procura de candidatos em 2013 e 2014, Tabela (1). 
Tabela 1: Relação candidato x vaga - Cursos PROEJA - IFFluminense campus Campos Guarus

\begin{tabular}{c|c|c|c|c|c|c}
\hline \multirow{2}{*}{ Ano Letivo } & \multicolumn{3}{|c|}{ Técnico em Eletrônica } & \multicolumn{3}{c}{ Técnico em Meio Ambiente } \\
\cline { 2 - 7 } & Vagas & № de Inscritos & $\mathrm{C} \times \mathrm{V}$ & Vagas & № de Inscritos & $\mathrm{C} \times \mathrm{V}$ \\
\hline 2007 & 40 & 34 & 0,85 & - & - & - \\
\hline 2008 & 40 & 78 & 1,95 & 40 & 84 & 2,10 \\
\hline 2009 & 35 & 93 & 2,66 & 40 & 119 & 2,97 \\
\hline 2010 & 35 & 127 & 3,63 & 40 & 131 & 3,27 \\
\hline 2011 & 35 & 92 & 2,63 & 40 & 87 & 2,17 \\
\hline 2012 & 35 & 87 & 2,48 & 40 & 89 & 2,22 \\
\hline 2013 & 35 & 118 & 3,37 & 40 & 187 & 4,68 \\
\hline 2014 & 35 & 155 & 4,43 & 40 & 194 & 4,85 \\
\hline
\end{tabular}

Fonte: Análise dos Resultados finais divulgados pela Comissão dos Processos Seletivos adaptado pela autora.

Conforme mostra a Figura (2), houve pouca variação entre os cursos na procura pelas vagas. Entre 2010 e 2012, houve maior procura pelo curso de Técnico em Eletrônica e nos outros períodos (2008-2009 e 2013-2014), houve maior procura pelo curso Técnico em Meio Ambiente.

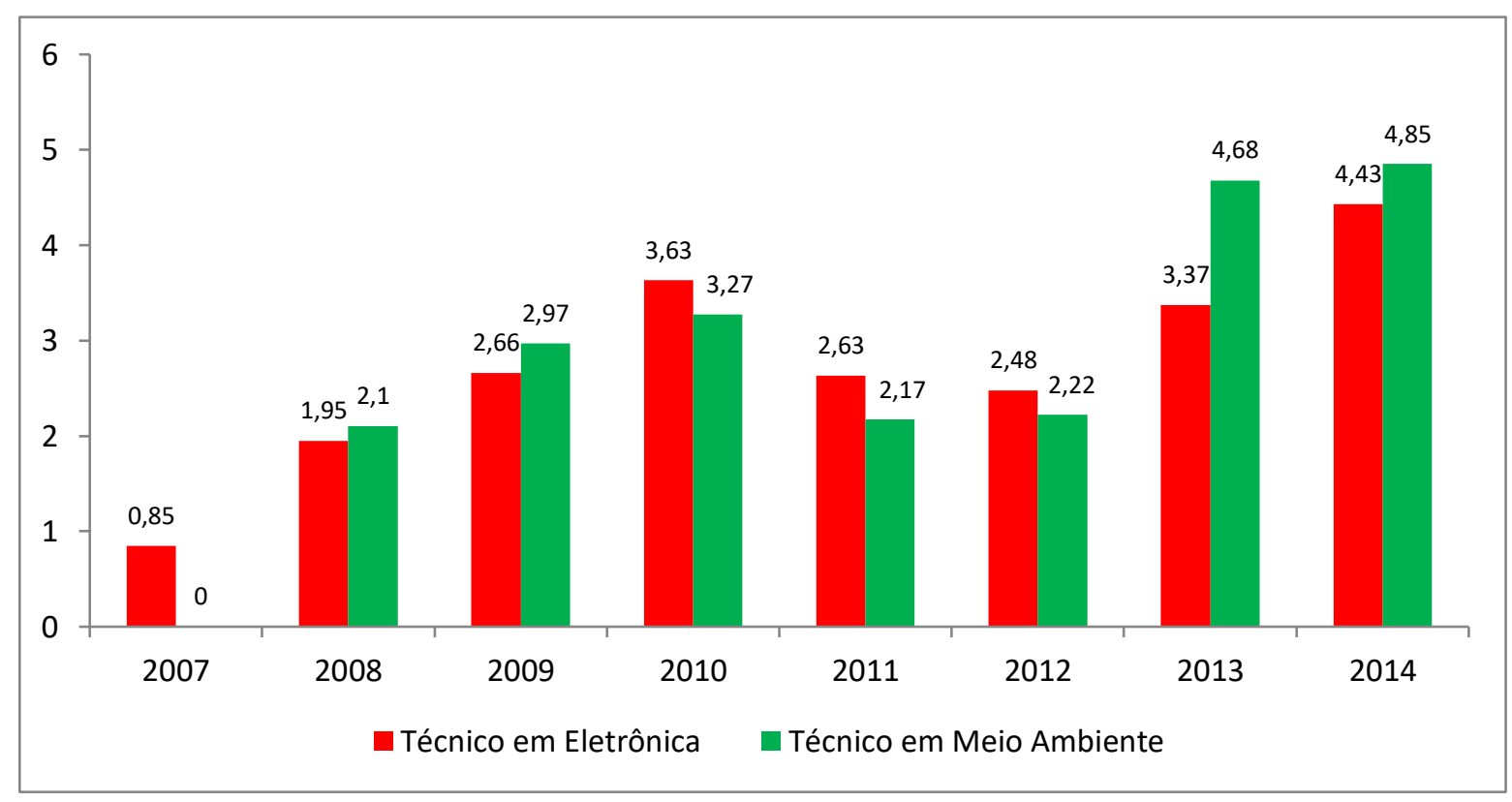

Figura 2: Relação candidato x vaga - cursos PROEJA - IFFluminense campus Campos Guarus - 2007-2014 Fonte: Análise dos Resultados finais divulgados pela Comissão dos Processos Seletivos elaborado pela autora.

$\mathrm{Na}$ análise dos resultados finais dos processos seletivos, foi possível observar que nos editais dos anos letivos de 2012 e 2014, os responsáveis pela Comissão do Processo Seletivo tiveram que lançar novos editais de vagas remanescentes, pois, apesar de a relação candidato $\mathrm{x}$ vaga registrar aproximadamente 2 candidatos por vaga em 2012 e 4 candidatos por vaga em 2014 (no somatório de candidatos inscritos nos dois editais), supõe-se que houve dificuldades para os candidatos compreenderem o edital de 2012 no que diz respeito: i) ao comparecimento na Instituição em dois momentos, para fazerem tanto a prova quanto a entrevista; ii) à forma de organização dos documentos comprobatórios solicitados na inscrição; e iii) ao cumprimento dos prazos exigidos no concurso. 
A título de comparação, apesar do contexto apresentado, há demanda por vagas no PROEJA de forma expressiva, se comparada com o universo total do IFFluminense. Em dados computados no Relatório Anual de Análise dos Indicadores de Gestão das Instituições Federais de Educação Profissional, Científica e Tecnológica no Exercício de 2014, o Instituto apresentou no indicador Relação de candidato por vaga, o índice de 1,88 candidatos a procura dos cursos em todos os seus campi. Portanto, pode-se avaliar que o PROEJA no campus Campos Guarus está com uma média superior e mais significativa, se comparado ao total geral da instituição.

No que diz respeito ao primeiro ano de oferta do PROEJA no campus Campos Guarus (2007), a divulgação do curso ficou comprometida devido ao fato de o campus estar sendo implantado naquele mesmo ano. Por isso, não alcançou nem 1 candidato por vaga, assumindo apenas 26 convocados das 40 vagas ofertadas. Analisando o período, percebe-se um maior equilíbrio em 2011 na relação número de convocados, reclassificados e faltantes para o curso Técnico em Eletrônica Figura (3).

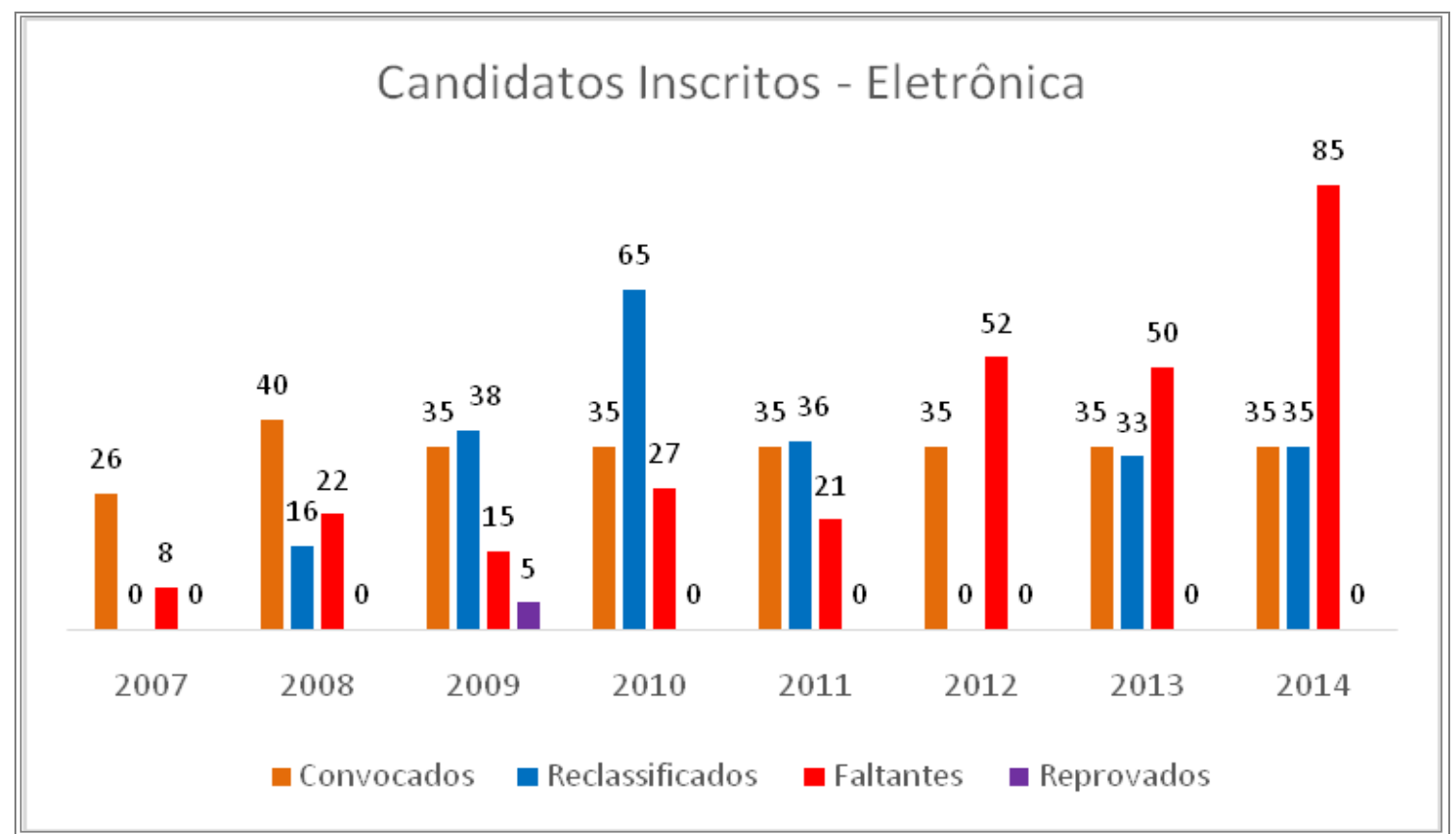

Figura 3: Levantamento de candidatos inscritos nos Processos Seletivos para as vagas nos cursos de Eletrônica do PROEJA - IFFluminense campus Campos Guarus

Fonte: Análise dos Resultados finais divulgados pela Comissão dos Processos Seletivos, elaborado pela autora.

Outro fato que chama a atenção para os dois cursos (Figuras 3 e 4) é o número significativo de faltosos a partir de 2012. É importante relatar que, com a tentativa de simplificação do processo seletivo e suas mudanças ano a ano já relatadas, houve maior procura de inscritos no período de 2013-2014. Entretanto, os procedimentos operacionais no contexto da escola para atender a clientela do PROEJA, tanto no que se refere ao atendimento vii, quanto ao que se refere às formas objetivas de potencializar as inscrições viii, são fatores que podem desmobilizar os candidatos pela falta desses serviços. 


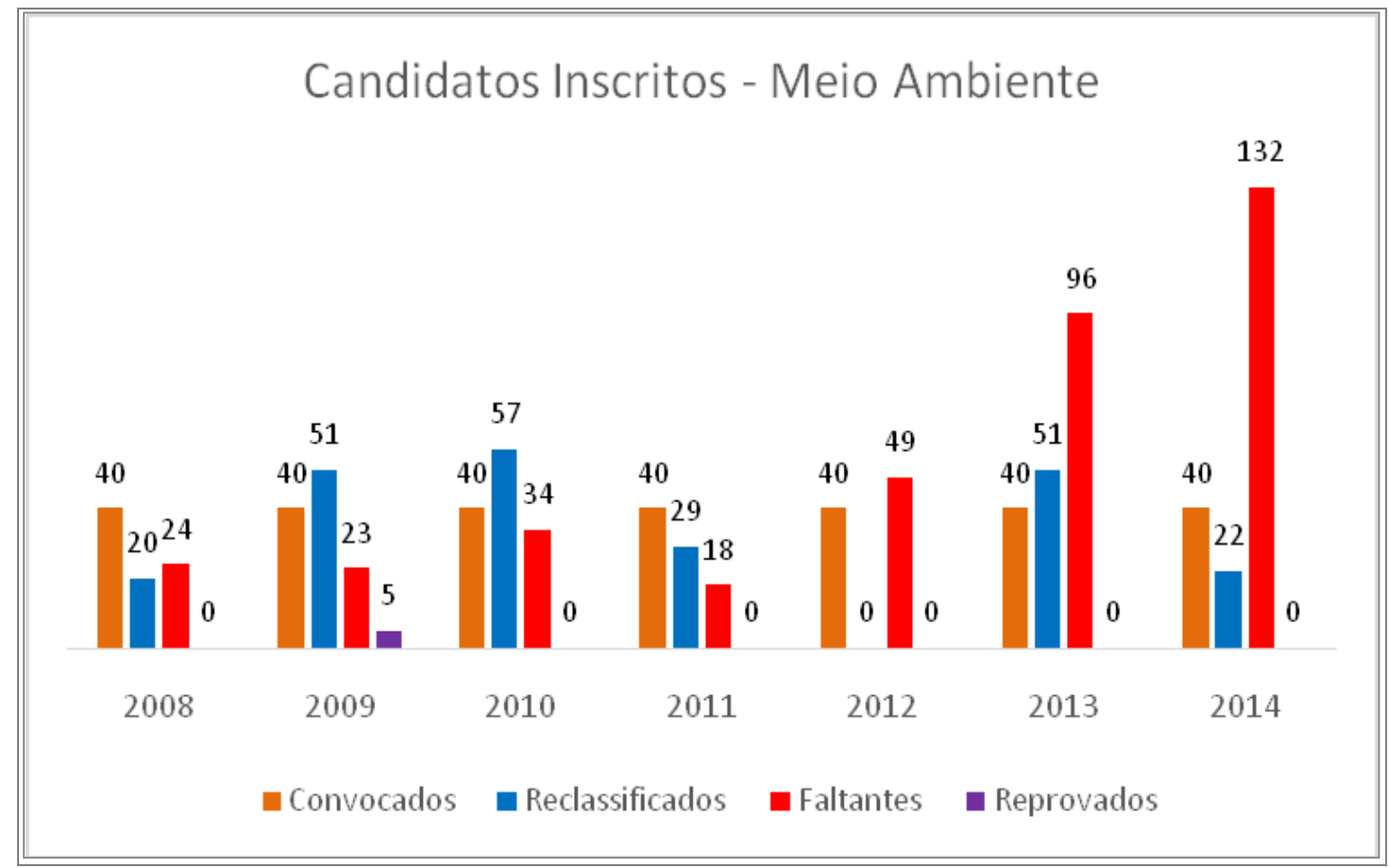

Figura 4: Levantamento de candidatos inscritos nos Processos Seletivos para as vagas nos cursos de Meio Ambiente do PROEJA - IFFluminense campus Campos Guarus

Fonte: Análise dos Resultados finais divulgados pela Comissão dos Processos Seletivos, elaborado pela autora.

As etapas e os resultados parciais e finais previstos nos editais são divulgados em datas previstas no calendário (cronograma) do respectivo documento, compondo a chamada pública para fins de comparecimento dos candidatos seguindo os trâmites ${ }^{i x}$ estabelecidos em cada processo seletivo, assim como o período de efetivação da matricula dos candidatos aprovados no setor do Registro Acadêmico no campus.

A divulgação da relação de classificados em ordem decrescente, conforme prevista nos editais, foi disponibilizada na Portaria do campus, no portal do IFFluminense ${ }^{\mathrm{x}}$ e na imprensa local' ${ }^{\mathrm{x}}$. Há previsão, no edital, de o candidato classificado ou reclassificado receber convocação por telefone ou telegrama, além da possibilidade da divulgação final ser feita via internet ou outro meio da imprensa local. Entretanto, o setor responsável para realizar essa atividade (Registro Acadêmico) não consegue seguir tal procedimento, pois geralmente as matrículas ocorrem concomitantemente com as matrículas dos outros cursos da instituição, gerando acúmulo de trabalho. Além desse, outros pontos de dificuldades devem ser considerados, entre eles, o próprio sistema (SISTEC ${ }^{\text {xii) }}$ utilizado para inclusão de novas matrículas no IfFluminense, que apresenta falhas de funcionamento e conexão e, consequentemente, sobrecarrega e atrasa os trabalhos dos servidores deste setor. Dessa forma, candidatos classificados e até mesmo os reclassificados perdem os prazos de efetivação de matrícula por desconheceram os procedimentos legais consolidados em edital.

Existe uma dificuldade interna institucional de "abraçar a causa", no sentido de potencializar a garantia do direito à educação para todos. Nesse direcionamento, se o público do PROEJA é constituído de jovens e adultos de classes populares, em sua maioria, trabalhadores que possuem problemas sociais e familiares e lutam pela conquista do retorno à escola, o atendimento a estes sujeitos pelo servidor público deverá ser com outro olhar, no sentido de entender suas dificuldades 
e de mobilizá-los para novas conquistas. Dessa maneira, ressalta-se que, segundo a entrevistada R., esse é um problema vivenciado no instituto, pois "não estamos conseguindo que o ser humano tenha essa sensibilidade e necessidade. Ele (o servidor) não tem que ser assistencial, mas ele tem que ser um profissional público para todos".

Não basta apenas oferecer as vagas para o público que o PROEJA almeja atender. A busca ativa pelos demandantes é um ponto importante em todos os espaços da escola, seja no momento do acesso, com a equipe da Comissão do Processo Seletivo ou com os servidores responsáveis pela matrícula, seja na sala de aula, com os respectivos professores, com os coordenadores de curso e toda a equipe que atende esse aluno no universo escolar, para que ele se sinta acolhido e mantenha acesa a vontade de permanecer no curso e ir adiante.

Na perspectiva de Haddad \& Ximenes (2014, p. 247), é necessário pensar nas condições de acesso e agir em prol do alunado para que o mesmo possa ter condições de frequentar os cursos voltados para a educação de jovens e adultos. De acordo com os autores:

[...] como sabemos, em grupos sociais pobres, excluídos de condições sociais básicas, com frustradas experiências escolares anteriores, não basta oferecer a escola, é necessário criar as condições de frequência, utilizando uma política de discriminação positiva, sob risco de mais uma vez culpabilizar os próprios alunos pelos seus fracassos. Mais do que isso é necessário promover a demanda a partir da oferta, pois ela vai se constituindo gradativamente pelo exemplo e a confiança daqueles que vão se incorporando aos sistemas de ensino.

Com base no panorama de acesso aos cursos do IFFluminense campus Campos Guarus ora apresentado, notamos que alguns procedimentos adotados precisam ser revistos e analisados pelos servidores envolvidos nesta ação. Apesar dos avanços realizados no período em questão, a fim de promover a inclusão daqueles que são o público alvo da política, nessa análise, verificamos que outras ações complementares serão necessárias para que de fato, possa garantir que, os coletivos excluídos que buscam a escola, ingressem nos cursos, permaneçam e efetivem seu direito à educação.

\section{CONSIDERAÇÕES FINAIS}

O PROEJA surge no campus Campos Guarus simultaneamente na fase de implantação do próprio campus. Entretanto, por determinação legal, o IFFluminense assumiu a obrigatoriedade de reservar $10 \%$ de suas vagas para o PROEJA, conforme orientou a Portaria n. 2080/2005 e o Decreto n. 5.840/2006.

Nesse contexto, os desafios estavam postos para um campus em processo de construção (estrutural e pedagógico) que assumia, naquele momento, a oferta do PROEJA, contando com o possível engajamento e competência daqueles novos servidores (docentes e técnicos administrativos), que também estavam ingressando na instituição.

Salientamos que os desafios inerentes ao PROEJA, requer a condução de um trabalho diferenciado por parte das instituições que o assumiram, pois se trata de uma modalidade da educação básica que integra a educação profissional ao ensino médio para a clientela da EJA, assumindo uma especificidade própria. Isso significa que 
[...] deve considerar a realidade do estudante e a proposição de um modelo pedagógico próprio, de acordo com o que está expresso nas Diretrizes Curriculares Nacionais para a EJA. Traz também consigo novos desafios principalmente do ponto de vista da necessidade de formação do educador, do pensar em práticas pedagógicas e de um currículo que leve em consideração as experiências e a realidade do aluno. (Arruda, 2012, p. 41).

Observando essas particularidades demandadas pelo PROEJA, outros aspectos singulares urgem visando a um tipo de atendimento, de acordo com o perfil dos sujeitos a serem atendidos. Por isso, nos detivemos em lançar mão do que foi operacionalizado na perspectiva do acesso dos estudantes aos cursos, analisando de que forma a instituição elaborou seus respectivos processos seletivos, pensando na realidade do educando, para qual o PROEJA se destina.

Ao traçar um panorama dos editais dos processos seletivos de acesso aos cursos do PROEJA no IFFluminense campus Campos Guarus, foi constatado que a gestão optou, durante um período considerável (2007-2011), pela aplicação de provas objetivas, conforme modelo dos vestibulares. Esse tipo de seleção, nos moldes tradicionalmente adotados, dificilmente abarcará o perfil daqueles que estão fora da escola há algum tempo, que tiveram uma formação no ensino fundamental com baixa qualidade e que estão desacreditados com relação a sua própria potencialidade em aprender.

A partir de 2012, iniciaram-se novos encaminhamentos e possibilidades de ingresso no PROEJA, com a adoção de novas estratégias institucionais, que tinham por objetivo assumir de fato a proposta de resgatar aqueles que "[...] foram excluídos do sistema educacional ou a ele não tiveram acesso nas faixas etárias denominadas regulares" (Brasil, 2007, p. 33), visando garantir o direito à educação.

A adoção de entrevistas, análise de documentos, aplicação de questionário socioprofissional, produção de textos e palestras se constituíram em ferramentas que, buscavam conhecer a realidade do candidato, que almejava o PROEJA, e direcionou a seleção de classificação, conforme os critérios preestabelecidos, que se atentava ao grupo destinatário da política.

De acordo com a análise, a partir de 2013 , a isenção de taxa de inscrição no processo seletivo e a Lei de Cotas n. 12.711/2012, foram medidas importantes que fortaleceram as mudanças implementadas no acesso aos cursos do PROEJA. Entretanto, percebemos que as dificuldades para efetivar o ingresso, permaneciam, quando detectamos um elevado número de candidatos faltosos, gerando a publicação de editais de vagas remanescentes.

A divulgação de edital de vagas remanescentes no PROEJA, ocasiona a realização de um novo processo seletivo que, no caso do campus Campos Guarus, foi feito por sistema de sorteio (fugindo da proposta previamente estabelecida). Além disso, esses editais extras são disponibilizados num período excepcional, provocando o ingresso dos candidatos nas respectivas turmas, após o início do ano letivo. Portanto, nessa situação, o ideal seria que as vagas inicialmente ofertadas, pudessem ser preenchidas por aqueles candidatos que se inscreveram dentro do perfil estabelecido a priori, evitando assim novos processos seletivos de vagas remanescentes.

No caso investigado, a demanda do PROEJA existe, pois identificamos que há um número significativo de candidatos inscritos nos processos seletivos. Contudo, há um grupo que efetivamente não integraliza sua inscrição, ou seja, faltam, ou não concluem até o final o procedimento. Isto é um sinal que deve ser percebido pela instituição, como um ponto de análise. 
De maneira ampla, a partir das mudanças relatadas nos processos seletivos do PROEJA no campus Campos Guarus, pontuamos as seguintes questões:

1- Não encontramos no período de 2012, 2013 e 2014 algum tipo de avaliação institucional que pudesse identificar se, as alterações realizadas no processo seletivo de acesso atingiram seus objetivos. Ou seja, as mudanças ocorreram em termos de gestão, e foram sendo implementadas nos campi que ofertavam o PROEJA. Entretanto, no campus Campos Guarus, não identificamos nenhum tipo de análise e reflexão a respeito inclusive com os servidores envolvidos nesse processo;

2- A Comissão de Processos Seletivos designada no campus necessitaria constituir uma equipe própria, para atuar especialmente no processo seletivo dos candidatos ao PROEJA. Essa mobilização poderia viabilizar as inscrições, por intermédio de orientações específicas sobre os editais, orientações sobre as documentações necessárias para o candidato apresentar no processo seletivo, esclarecimentos de dúvidas a respeito de prazos e desvelamento de questões relacionadas aos cursos oferecidos, bem como sobre a estrutura organizacional da instituição; e

3- Identificamos a falta de articulação no processo de divulgação dos cursos, atrelada à sistematização e acompanhamento dos inscritos. Uma ação nesse sentido poderia intensificar a busca de candidatos em locais específicos, que pudessem firmar parcerias, como por exemplo: a Secretaria de Assistência Social do Município de Campos dos Goytacazes, os Centros de Referência de Assistência Social - CRAS, as Associações de Moradores, as Escolas Estaduais e Municipais que oferecem EJA, entre outras instituições.

A respeito deste último item, acreditamos que uma possível intervenção na questão do acesso aos cursos do PROEJA, poderia ser alinhavada com uma proposta intergovernamental, cuja implementação submete-se ao "desafio de lidar com a interdependência e com a autonomia das esferas de governo em sua ação no campo da educação, e com a inclusão e a articulação de múltiplos atores da implementação, situados em espaços geográficos e institucionais diversos e múltiplos" (Farenzena \& Luce, 2014, p. 212).

Os aspectos levantados que emergiram a partir desta pesquisa, sinalizam possíveis alternativas que, podem se configurar como estratégias que aglutinam elementos do acesso com vistas à permanência dos estudantes no IFFluminense campus Campos Guarus.

\section{REFERÊNCIAS}

Arroyo, M. G. (2003). Da Escola Carente à Escola Possível. (6a ed., p. 9-52). São Paulo: Loyola.

Arroyo, M. G. (2011). Educação de jovens e adultos: um campo de direitos e responsabilidade pública. In: Diálogos na educação de jovens e adultos. (4a ed., p. 19-52). Belo Horizonte: Autêntica editora.

Arroyo, M. G. (2011). Políticas educacionais, igualdade e diferenças. Revista Brasileira de Política e Administração da Educação, Periódico científico editado pela ANPAE, 27(1), 83-94. 
Arruda, Z. A. de A. (2012). O PROEJA no IFPB campus João Pessoa: um estudo sobre o acesso e a permanência do alunado. 145p. Dissertação de Mestrado em Educação, Universidade Federal da Paraíba, João Pessoa/PB.

Brasil. (2007). Programa de Integração da Educação Profissional Técnica de Nível Médio Integrada ao Ensino Médio na Modalidade de Educação de Jovens e Adultos - PROEJA. Documento Base.

Campos dos Goytacazes, RJ (2006). Edital n. 011/2006. Ensino Técnico UNED Guarus - Processo seletivo 2007. 24p.

Campos dos Goytacazes, RJ (2007). Edital n.o 020/2007. Ensino Técnico UNED Guarus - Processo seletivo 2008. 32p.

Campos dos Goytacazes, RJ (2009). Edital n.o 014/2008. Ensino Técnico UNED Guarus - Processo seletivo 2009. 41p.

Campos dos Goytacazes, RJ (2009). Edital n.o 14/2009. Ensino Médio e Técnico campus CamposCentro, campus Campos-Guarus, campus Itaperuna, campus Cabo Frio, campus Bom Jesus do Itabapoana e Núcleo Avançado de Quissamã - Processo seletivo 2010. 33p.

Campos dos Goytacazes, RJ (2010). Edital n.o 20/2010. Ensino Médio e Técnico campus CamposCentro, campus Campos-Guarus, campus Macaé, campus Itaperuna, campus Cabo Frio, campus Bom Jesus do Itabapoana e campus Avançado de Quissamã e Núcleo Avançado de Cambuci Processo seletivo 2011. 37p.

Campos dos Goytacazes, RJ (2011). Edital n.o 32/2011. Ensino Médio e Técnico campus CamposCentro, campus Campos-Guarus, campus Macaé, campus Itaperuna, campus Cabo Frio, campus Bom Jesus do Itabapoana e campus Avançado de Quissamã e Núcleo Avançado de Cambuci Processo seletivo 2012. 33p.

Campos dos Goytacazes, RJ (2012). Edital n.o 19/2012. Aproveitamento de vagas remanescentes do Processo Seletivo 2012 para cursos Técnicos do PROEJA - campus Campos-Centro, campus Campos-Guarus e campus Macaé - Processo seletivo 2012. 4p.

Campos dos Goytacazes, RJ (2012). Edital n.o 130 de 26 de outubro de 2012. Processo Seletivo para ingresso aos cursos Técnicos de Nível Médio Integrado à Educação Básica na Modalidade de Jovens e Adultos - PROEJA, Processo seletivo 2013. 23p.

Campos dos Goytacazes, RJ (2013). Edital n.o 127 de 11 de setembro de 2013. Processo Seletivo para ingresso aos cursos Técnicos de Nível Médio Integrado à Educação Básica na Modalidade de Jovens e Adultos - PROEJA, Processo seletivo 2014. 30p.

Campos dos Goytacazes, RJ (2013). Edital n.o 152 de 31 de outubro de 2013. Processo Seletivo para ocupação de vagas remanescentes para os cursos Técnicos de Nível Médio Integrado à Educação Básica na Modalidade de Jovens e Adultos, Processo seletivo 2014. 27p.

Campos dos Goytacazes, RJ (2014). Edital n.o 133 de 29 de setembro de 2014. Processo Seletivo para ingresso aos cursos Técnicos Integrados ao Ensino Médio na Modalidade de Jovens e 
Adultos - PROEJA, Processo seletivo 2015. 34p.

Coutinho, E. H. L. (2012). Trajetória escolar dos alunos do proeja no CEFET-MG e as possibilidades de inclusão social. In: Seminário Nacional de Educação Profissional e Tecnológica. Recuperado em 12 fevereiro, 2016, de http://www.senept.cefetmg.br/galerias/Anais_2012/GT-07/GT07006.pdf

Coutinho, E. H. L. (2010). Inovações socioeducacionais e o processo seletivo dos cursos técnicos integrados do CEFET-MG. Dissertação (Mestrado em Gestão Social). Curso de Pós-graduação em Gestão Social. Educação e Desenvolvimento Local. Centro Universitário UMA.

Farenzena, N., \& Luce, M. B. (2014). Políticas públicas de educação no Brasil: reconfigurações e ambiguidades. In: Madeira, L. M. (Org.). Avaliação de Políticas Públicas. (p. 195-215). Porto Alegre: UFRGS/CEGOV.

Frigotto, G. (2010). A relação da educação profissional e tecnológica com a universalização da educação básica. In: Educação Profissional e Tecnológica no Brasil Contemporâneo: desafios, tensões e possibilidades. (p. 25-41). Porto Alegre: Artmed.

Gil, A. C. (2002). Como elaborar projetos de pesquisa. (4a ed., pp. 41-56). São Paulo: Atlas.

Haddad, S., \& Ximenes, S. (2014). A educação de pessoas jovens e adultas na LDB: um olhar passados 17 anos. In: Brzezinski, I. (Org.). LDB/1996 contemporânea: contradições, tensões, compromissos. (p. 233-255). São Paulo: Cortez.

Lemos, S. F. C. (2010). Programa Nacional de Integração da Educação Profissional com a Educação Básica na Modalidade de Educação de Jovens e Adultos (PROEJA): um estudo sobre o acesso à formação profissional. Dissertação (Mestrado em Educação) - Universidade Estácio de Sá, Rio de Janeiro, RJ.

Lima Filho, D. L. (2010). O PROEJA em construção: enfrentando desafios políticos e pedagógicos. Educação e Realidade, 35(1), 109-127.

Moll, J. (2010). PROEJA e democratização da educação básica. In: Educação Profissional $e$ Tecnológica no Brasil Contemporâneo: desafios, tensões e possibilidades (pp. 131-138). Porto Alegre: Artmed.

Selltiz, C.; Cook, S., \& Wrightsman, L. (1975). Métodos de Pesquisa nas relações sociais. (5a ed., pp. 263-311). São Paulo: E.P.U.; Ed. UDUSP.

Wandroski, S. F., \& Colen, F. R. C. (2014). As ações afirmativas para ingresso de estudantes no Instituto Federal de Educação, Ciência e Tecnologia de Rondônia. O Social em Questão - Ano XVII, 32, 165-182.

\footnotetext{
'A pesquisa foi realizada no ano de 2015. O período selecionado de 2007 a 2014 refere-se ao início da oferta de cursos PROEJA até o último edital de vagas disponível no momento de execução da pesquisa.

ii Prova com questões objetivas de múltipla escolha.

iii Foram convocados para entrevista, três vezes o número de vagas ofertadas de cada curso do PROEJA.
} 
iv O edital de vagas remanescentes (n. - 19/2012) foi elaborado para atender 8,5\% das vagas ociosas do curso Técnico em Eletrônica e 35\% das vagas ociosas do curso Técnico em Meio Ambiente no campus Campos Guarus. Neste último edital, foi adotado o sorteio público como critério para seleção dos candidatos.

${ }^{\vee}$ Este critério foi adotado na perspectiva de atender prioritariamente os moradores residentes na circunvizinhança e arredores do campus Campos Guarus, pois a criação do campus nesta localidade tem relação com a possibilidade de atendimento à população daquela região/distrito.

vi O edital n.o 152/2013 ofereceu 25 vagas remanescentes (13 vagas - Técnico em Eletrônica e 12 vagas - Técnico em Meio Ambiente) e seguiu os mesmos critérios e procedimentos de seleção previstos no edital n. $0127 / 2013$ para ingresso no ano de 2014.

vii Mobilização de uma equipe própria no campus para atuar no processo seletivo dos candidatos ao PROEJA, orientando nas inscrições e especificações de documentos que devem ser apresentados, como também no cumprimento de prazos e desvelamento de questões relacionadas aos cursos oferecidos.

viii Verificação e acompanhamento de número de inscritos para busca ativa na divulgação em locais como Secretarias de Assistência Social do Município, Centro de Referência de Assistência Social - CRAS, Associação de Moradores, etc.

ix Comparecimento para realização da prova objetiva; comparecimento na entrevista; entrega do questionário socioprofissional; entrega de documentos comprobatórios exigidos em edital; comparecimento para realização da produção textual; comparecimento na palestra sobre o PROEJA.

${ }^{x}$ Acessar em: www.iff.edu.br

xi A divulgação na imprensa local ocorreu no período de 2007 a 2011. Neste caso, em 2012, 2013 e 2014, podem ter ocorrido maiores dificuldades para os candidatos acompanharem o desenvolvimento do processo seletivo.

xii Sistema Nacional de Informações da Educação Profissional e Tecnológica. 